\title{
ABRAHAM, a Semiautomatic Trainable Connoisseur Lab, as a Big Data Collection Platform
}

\author{
Michael Agrafiotis \\ Department of Business Administration, West Macedonia Univ of Applied Sciences, 50100 \\ Kozani, Greece
}

\begin{abstract}
Athanasios Zisopoulos (Correspondence Author)
Faculty of Mathematics and Informatics, University of Sofia Saint Kliment Ochridsky, Blvd “James Bourchier" 5, 1164 g.k. Lozenets, Sofia, Bulgaria
\end{abstract}

Konstantinos Spinthiropoulos

Department of Business Administration, West Macedonia Univ of Applied Sciences, 50100 Kozani, Greece

Received: December 8, 2018 Accepted: January 26, 2019 Published: January 30, 2019

doi:10.5296/jfs.v8i1.14302 URL: https://doi.org/10.5296/jfs.v8i1.14302

\begin{abstract}
The main idea of the invention is an expert system to execute a specific recipe through a food container and a moving and tilting pot with gases and visible cooking analysis. Details used to achieve professional results are: food preprocessing and weighted, normal warehouse, fridge, and deep fridge, overall positioning, computer control, monitoring the cooking gases and light spectrum and trainability. The machinery line has been designed for the semi-professional market but it has capabilities for catering, military operation, gourmet cooking and serving. The modular design permits an entry system with a few food containers, two pots, an oven and the base software running on a single PC while the advanced option uses thousands of food boxes, tenths of pots, pans, ovens and high expert systems intelligence running on real time industrial computers. All these give unlimited futuristic capabilities covering the 10-year time for Return on Investment. The cooking on this machine is a statistical Big Data cooking with Data Science principles.
\end{abstract}

Keywords: Cooking, Connoisseur lab, Data science, Mechatronics, Sensors, Positioning, Gastronomy, Big data, Cooking gases, Semi-automatic robots, Machine training, Cooking command language, Food packaging, Nutrients calculation, Recipe preparation 


\section{Macrothink}

\section{Introduction}

Our research technical field areas are: Food preparation, Catering, Cooking, Electronics, sensors, Logistics, Restaurant and leisure industry. The last few years a number of patents has been granted with similar automatic cooking subject: Robot, control apparatus, and control method; Apparatus for producing a food item; Heterogeneous fleet of robots for collaborative object processing; Method for Conducting at Least One Cooking Process; Food cooking machine; Food cooking apparatus; Electric wok having food processor with automatic feed.

All these are studied but they create more problems than they solve. The only drawback they do have is that they cannot design for the future.

The main idea of the invention co-integrates an expert-computer system to execute a specific recipe through a food container and a moving- tilting pot with gases and visible cooking analysis. Details used to achieve actual results are: triple food warehouse normal, fridge, and deep fridge (Boysen, 2018, Chang, 2007, Cinar, 2017, Nicolas, 2018); RFID tagging for positioning (Royo, 2013, Brandl, 2016); Wi-Fi devices connection and central computer control for all kitchen components (Doiro, 2017); trainable cooking procedure both from operator console and through software packages resembling a cooking action (Schneider, 2007, Hamada, 2005).

Global current technology is very advanced. They present products for home automation cooking and huge machinery lines for the leisure industry. Nevertheless, there are not similar efforts and developments for semiprofessional market. The invention is modular and the user could start with a few containers, two pots, an oven and the base software running on a single PC. With that entry level little kitchen, the chef can execute the same recipe on demand for every customer. Even in the basic system offers unlimited variations on salt, special expensive oil dressing, extra herbs, overcooking, and thousands other options. All these are added to the recipe text in the computer and stored as "love potion number 9" (Pereboom 2009). This can be repeated or improved any time later. The advanced system has unlimited futuristic capabilities covering the 10-year time for ROI (Return on Investment).

Mathematical cooking did not gain researcher attention. Jones (2008) uses elementary mathematic calculation for recipe preparation. Barham (2001) defines cooking in a descent scientific approach. Other researchers face the nutrition aspect of cooking (This 2010, Erasmus 2013, Marcus 2013). Even Albert Einstein said about kitchen science (Wolke, 2002).

Searching the history for a brand name we found that the first Holy Trinity appearance to mankind was like this: (Genesis 18).

Table 1. Food preparation for Holy Trinity

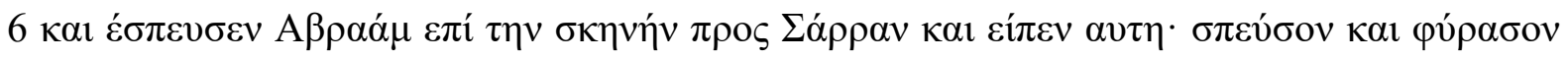

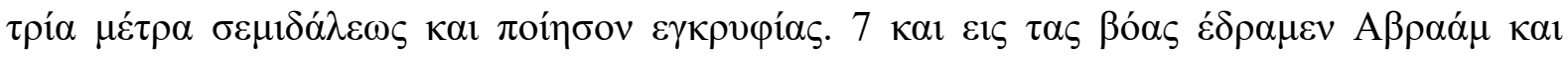

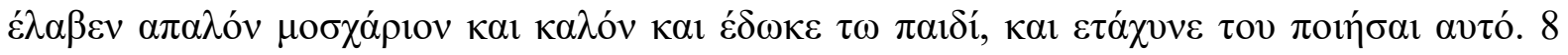

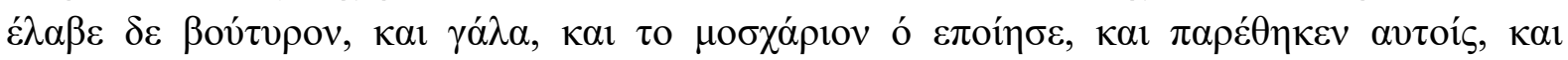

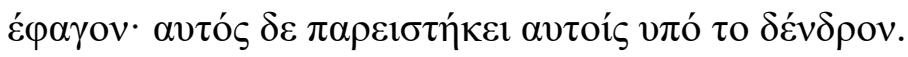

6So Abraham hurried into the tent to Sarah. "Quick," he said, "get three seahs $\stackrel{b}{\text { b }}$ of the finest 


\section{I Macrothink}

flour and knead it and bake some bread." $\underline{7}$ Then he ran to the herd and selected a choice, tender calf and gave it to a servant, who hurried to prepare it. $\underline{\mathbf{8}} \mathrm{He}$ then brought some curds and milk and the calf that had been prepared, and set these before them. While they ate, he stood near them under a tree.

We give the Abraham name to our connoisseur lab from this Bible lemma with detailed food preparation some 4000 years ago.

\section{Drawings}

To reveal our design, we attach 9 drawings.

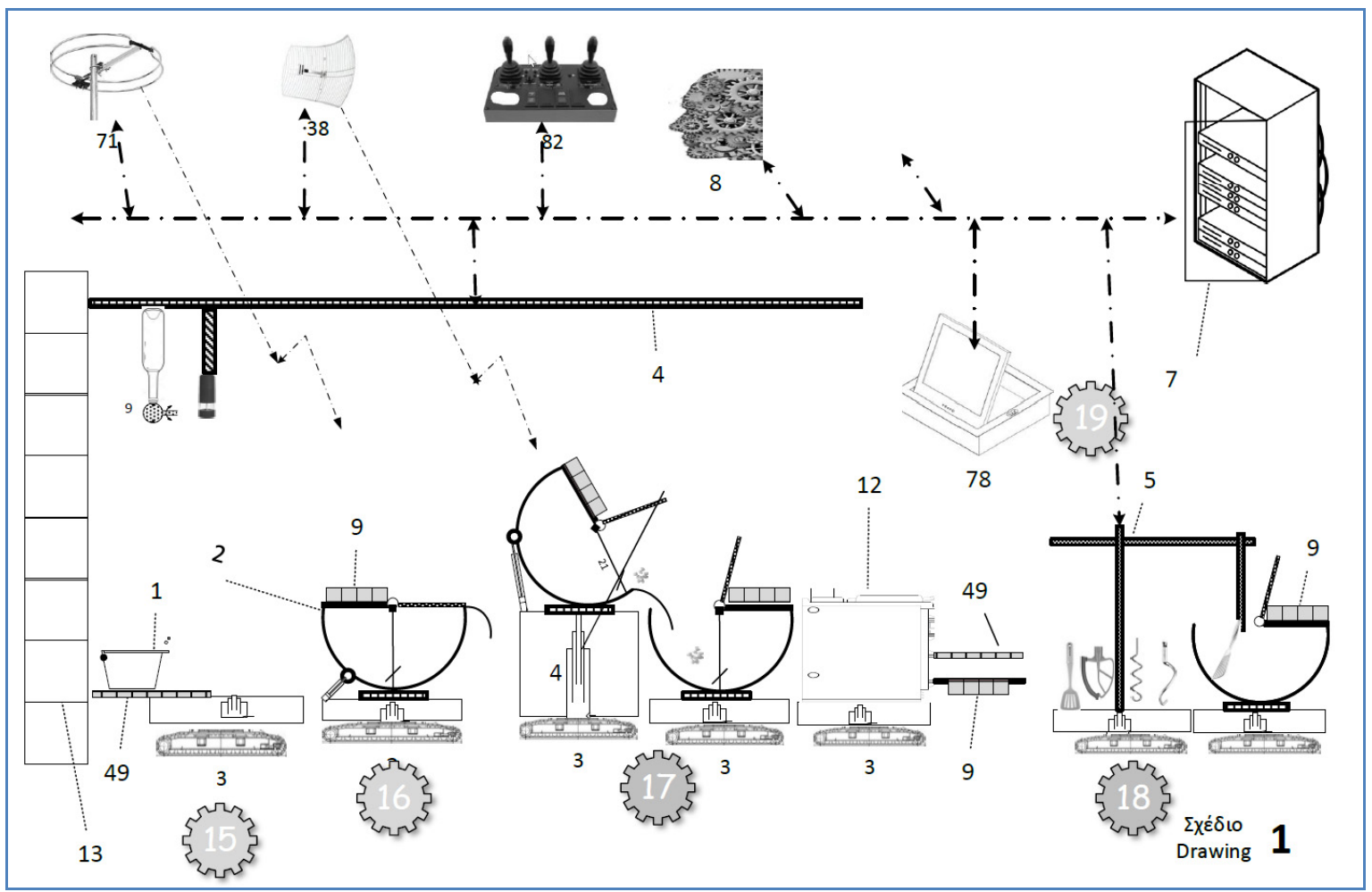

Figure 1. Invention general layout

A food container (1) in a storeroom (13); a tilting cooking pot (2); a multisensory box (9) with gases spectrum analyzers and cameras; a general purpose in kitchen vehicle (3) carrying around all the cooking vessels, pots and pans (12); an under the ceiling positioning system (4) to deliver liquids in bottles and spices in mills; a cooking finisher (5) with six axes; an in kitchen positioning finding system (6); a central kitchen computer (7); a radio frequency connection to the computer (7); through the aerial (38).; liquids and spices heads $(41,42)$; vehicles (3); cooking pots (2); a number of antennas (71,38); positioning software and connection to the computer (7) giving the exact spatiotemporal coordinates around the kitchen; a trainable expert system (8); a message warning monitor (78); recipe execution steps: food fetching (15), cooking (16), transfer (17) to another cooking vessel, cooking finishing (18) and emergency manual intervention (19). 


\section{MInstitute Macrothink $^{\text {Int }}$}

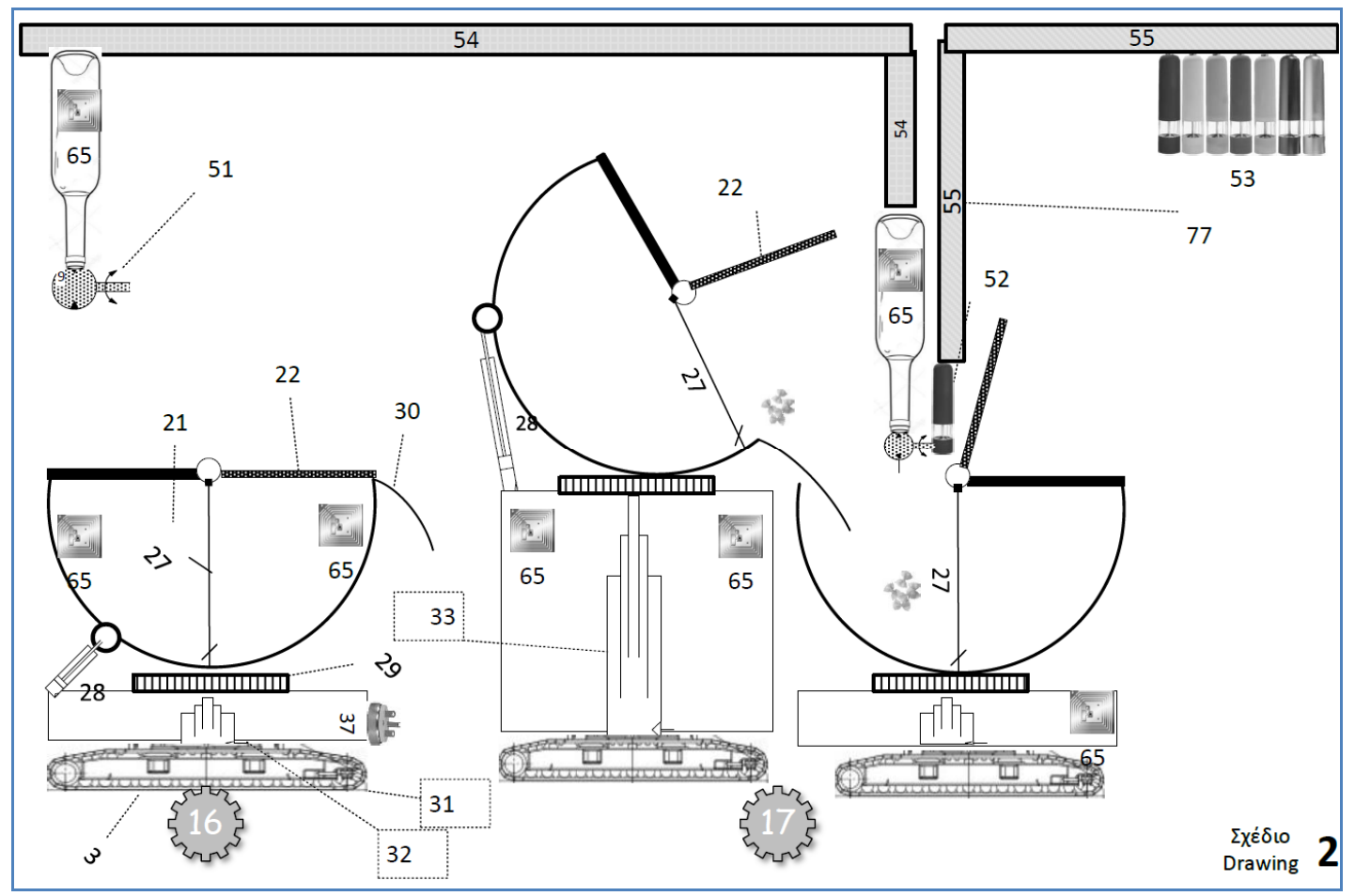

Figure 2. The cooking procedure

The general purpose in kitchen vehicle (3); a travelling crawler (31); a vehicle elevating body (32); a telescopic elevating actuator (33); a cooking hot surface (29); a hemisphere (21) boiler; an openable cover (22); a stirrer in emptying wide mode (27); a number of positioning labels (65); a guidance system (36) with motors and batteries; an industrial AC connection (37); The under the roof three axis positioning system (4); a dosing pump (51) attached to any bottle or tank; a dosing mill (52); for herbs and spices (53); the capability to deliver the ejecting ingredient to any point in the kitchen through a 3 axis movement actuators; tanks and bottles (54) herbs and spices (55).

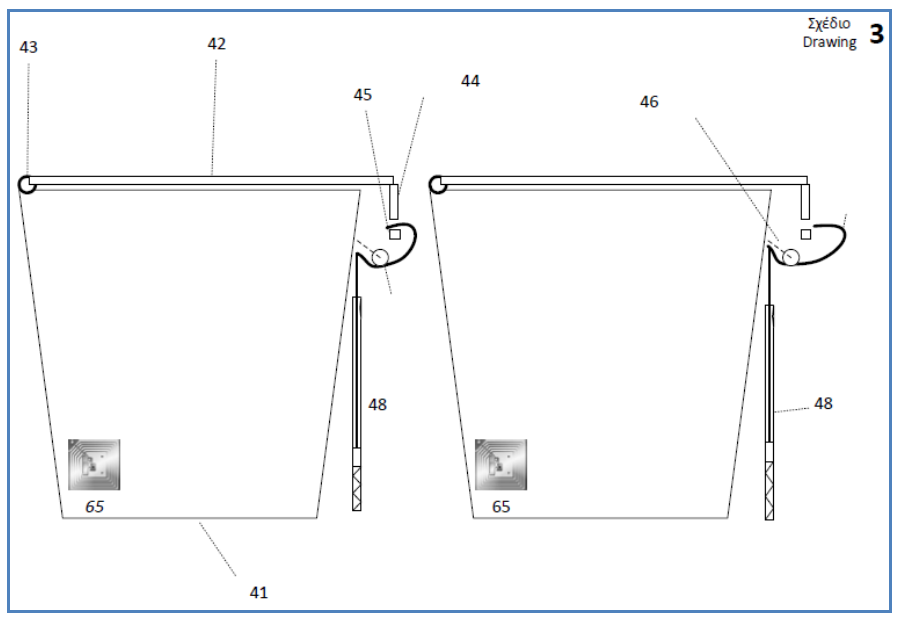

Figure 3. The food container

The food container (1); a positioning label (65) stapled to a ; trapezoid food box (41) with ; a cover (42) firmly connected to; hinges (43); a latch (44) under the edge of the cover; a hook (45) firmly attached at the box main body with; a spring (46) and; a release end (47); to be 


\section{Macrothink}

pushed by the actuator (48).

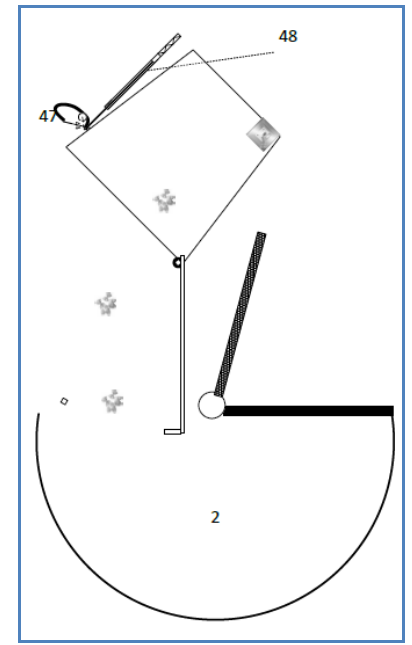

Figure 1. Unloading food from the storage to the pot

-Procedure 15; The actuator (48) already elevated.

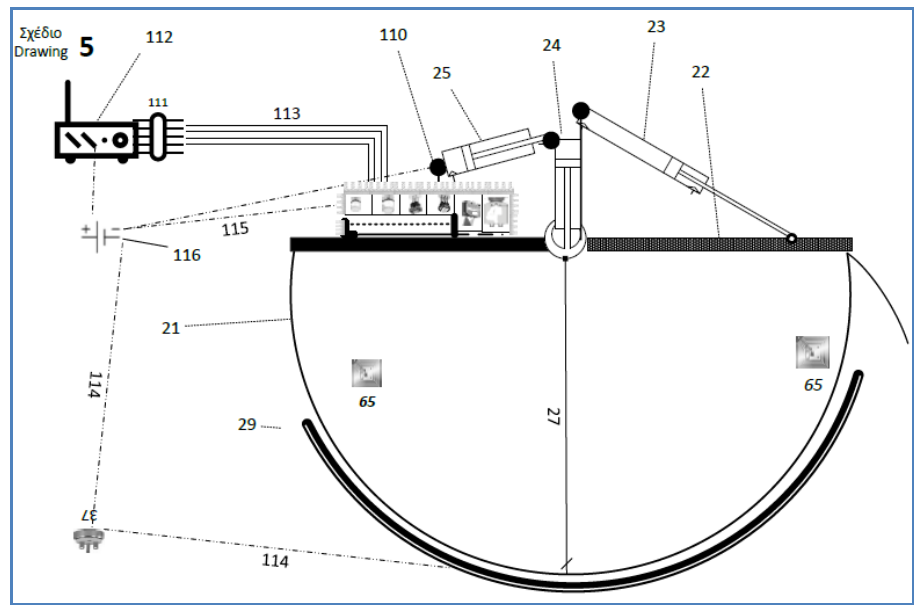

Figure 2. Pot (2) detailed description

The tilting cooking pot (2); a hemisphere (21) boiler; a cooking hot surface (29); a cover (22) to be opened by the actuator (23); a mixing (26) or emptying (27) stirrer to be mode alternated ; by the actuator (24); a stirrer rotated by the actuator (25); a free hanging tongue (30) to unload to other cooking vessels (12).; An unmovable elevated hinges spot (110) where actuators are hanged with unlimited movement freedom.; Data concentrator (111); Pot and vehicle telecom device (112); Data lines (113); DC low voltage lines (115); AC high voltage lines (114).

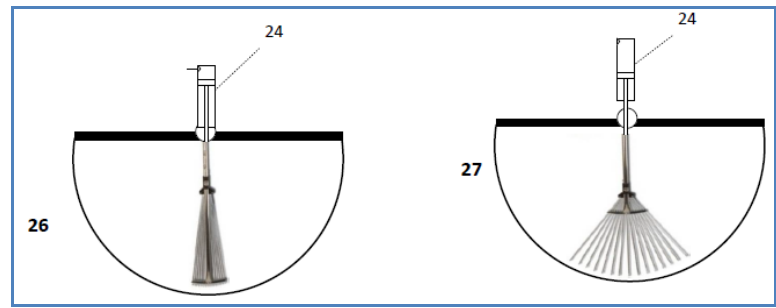

Figure 6. The two mixing-emptying options 


\section{Macrothink}

- Up down actuator (24); Wide position (27) inside the pot (2); • Slim position (26).

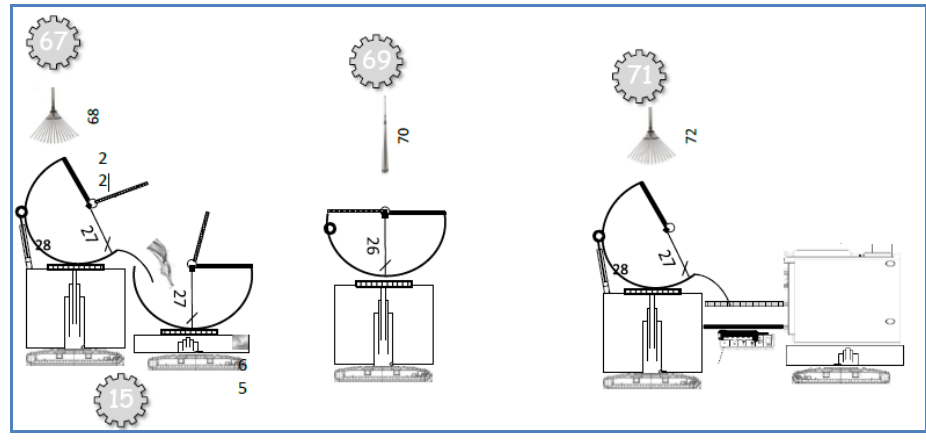

Figure 3. A a new deep fryer with intelligent use existing hardware

The initial phase (67) unloading the oil to another pot.; The stirrer in position wide (68) ejecting only the oil.; The second phase (69) stirrer to return through the already fried potatoes.; The stirrer in position narrow (70) and returns in the starting position.; The third phase (71); The stirrer in position wide (72); The stirrer pushes the potatoes to the oven (12).

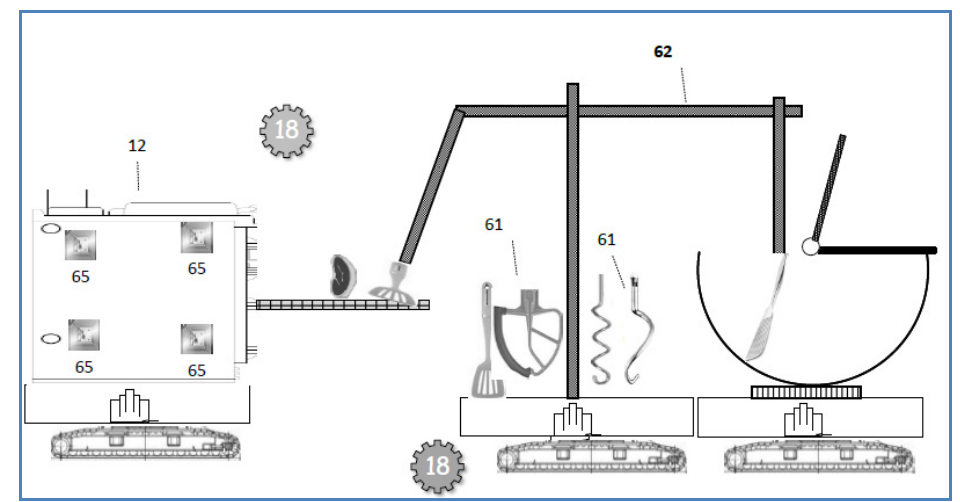

Figure 4. The hand operated cooking finisher

The cooking finisher (5); cooking finishing (18) procedure in the oven drawer; a six axis actuator schema (62); interchangeable working heads (61).

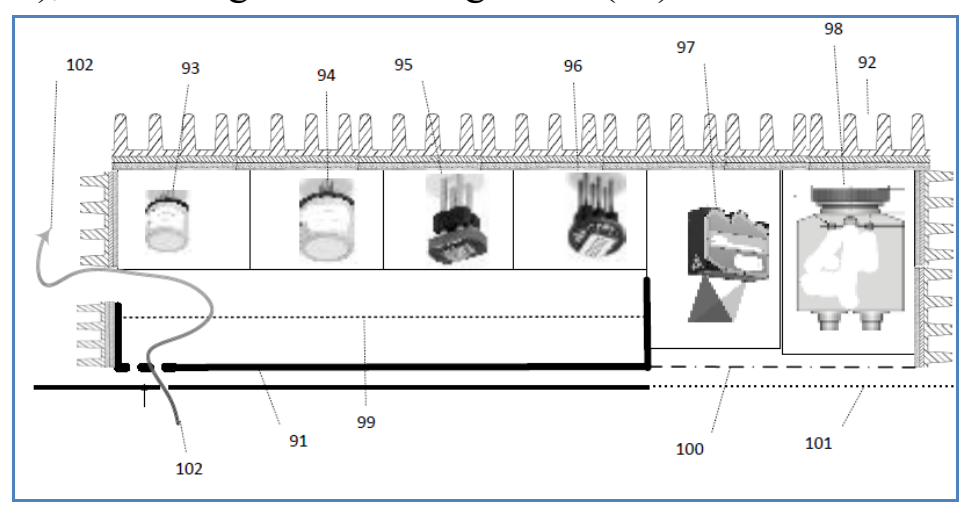

Figure 5. Multisensor measurement cover pot

The multisensory cover box (9); a thermal isolation shield (91) over the glass unmovable top of the pot (2); all around heatsinks (92); calibrated carbon monoxide gas sensor (93); Calibrated Ethylene gas sensor (94); gases temperature, humidity and pressure sensor (95); NO2 gas sensor (96); food surface precision pyrometer (97); thermal imager (98); Gases grid 
to slow down outflow (99); Box Glass cover (100); Pot cover from glass (101); Air flow from inside out (102).

\section{Functionality}

The small container (1) is the only automatic food intake methodology. The containers storage warehouse has three departments one for normal food, a fridge for fresh products and the third for deep fridge lots.

At the preprocessing stage the food is divided in cooking portions at different sizes. Every small or bigger portion is placed inside the box (1). The filling operator executes the following steps:

- Initially he fills in an industrial terminal the food general data like type, quality, associated invoice, special order data etc.

- The operator divides the food into desirable chunks and put every chunk in a container (1).

- He puts the container into a scale. There automatically the container is weighted, a RFID tag (65) is attached

- and the vehicle (3) drawer (49) grabs it.

- When the lift is full with food boxes, it is positioned into his final destination shelf (13)

The container is a trapezoid box (41) with a cover (42) firmly connected to hinges (43), a latch (44) under the edge of the cover, a hook (45) firmly attached at the box main body with a spring (46) and a release end (47) to be pushed by the actuator (48).

The closed container has two functioning stages. It remains locked until it reaches the point above the cooking pot (drawing 3,4). There it proceeds to the second stage, where the actuator (48) pushes the low edge of the hook (45) and the latch opens the cover (42).

The now open container is tilting above the open pot (2) and it unloads the content for further processing.

The moving-tilting pot (2) functionality is the basis of the recipe execution. Actual cooking needs a lot more than one pots. All system parts that come in contact with the food are detachable in order to be washed. The pot has two stages, cooking and food loading and unloading.

The tilting cooking pot (2) in normal cooking stage is placed on top of a kitchen vehicle. It has a hemisphere (21) boiler, placed on top of a similar shape hot surface (29), a firmly closed cover (22), a mixing (26) stirrer. From time to time, only after central computer (7) commandment, the stirrer is pushed (or pulled) by the actuator (25). This is the first pure cooking stage.

The second stage starts when both the vehicle (3) with the pot on top move up to the point of food interchange. There the telescopic heavy actuator (33) elevates the pot to desired high point. Then the side actuator (28) tilts the pot (21) to an inclined position. The actuator (23) pulls and it opens the cover (22).

The actuator (24) pushes the stirrer in wide position (27), the actuator (25) pushes the stirrer and all pot ingredients are carried away to free hanging tongue (30) and to the underneath pot or oven.

The pot (1) to achieve full functionality share with the vehicle (3) data lines $(111,113)$, 


\section{Macrothink}

telecom lines $(112,38), \mathrm{DC}$ and AC currency lines $(115,114)$.

The fully equipped kitchen vehicle (3) carries all pots, pans, ovens and finishers around the cooking area. The vehicle hosts the electrical computer and data signaling with associated pot and all kitchen movable equipment. It also hosts the battery (116), crawler or wheels, the telescopic heavy electric actuator (33), the socket to connect to kitchen AC currency. Inside the vehicle embedded more than one tags. They report positioning data to the aerial (71). The computer transmits (38) detailed relocation instruction to the motors of the vehicle (two for crawler four for wheel version). The motor runs and the vehicle arrive to the new position with accuracy of $2 \mathrm{~mm}$.

It is important here to clarify once more that the vehicle is a dump moving crawler. It cannot see collisions, it could travel with an open pot spreading around hot oil, if the computer forgets to close it.

The general functionality of the invention is rather complex. The simplified approach is that everything is controlled by the computer (7) and the associated expert system provides the necessary intelligence.

In an initial simple example to boil spaghetti, machinery steps are:

1. In a preliminary phase the operator put pasta inside the container (1).

2. The expert system accepts a command to execute recipe number 1345 . It sends to the computer the steps in a pseudo code.

3. The computer reads the code and executes it one step at a time. (although it is possible to prepare altogether the sausage for the same recipe, the machine has unlimited capacity

4. The vehicle (3) approaches the warehouse (13) ejects the drawer (49) and grabs the pasta container (1).

5. The computer commands the pot (2) to pull actuator (23) and the cover (22) opens.

6. The water tank travels through the axis system (54) and ejects volumetrically 2 liters of water into the pot (1).

7. The computer turns on the heat plate (29) and the water is boiling.

8. The vehicle with the container (1) approaches side by side to the pot and the actuator (32) elevates the container.

9. The actuator (48) increases and the lock opens.

10. The pasta container (1) is unloaded into the boiling water pot according to procedure (15)

11. The actuator (23) pushes the cover to close and pasta is prepared.

In a similar manner the water is unloading and a bottle oil is fetched through the axes system and the spaghetti is ready.

Other apparatus subsystems are:

- The cooking finisher

- Analyzing the cooking gases and full electromagnetic spectrum.

- The commandments and communications flow

- The guided cooking by a chef.

- The expert system 


\section{Ml Macrothink}

The cooking finisher improves not exact and usual cooking procedures. The cooking finisher does what all other sub systems cannot perform. This inability to execute the recipe has two steps: error finding and healing.

The first is to define the abnormality after manual or computer warnings. Sometimes the chef-operator sees in the kitchen area something not usual. A lot of times the expert system (8) finds a recipe conflict, an unsupported action or a temporary runout. In all cases a warning command is send to the manual intervention monitor (78).

The second step is to proceed for error correction. There are a lot of types of such manual actions. In an emergency the operator presses the panic button, he suspends the whole cooking and he walks in the kitchen area to the faulty point. In some cases, this manual involvement could be also accomplished by selecting from the main console (82) an appropriate predefined, software enabled, actions. The operator sees a list of 30 actions. He selects the one saying: "arm the cooking finisher with a bread steering tool, proceed at pot number 8B and stir at the lowest possible rate in contact with the pot surface". So, it is done.

Another example is when sometimes a heap of potatoes is created after pot tilting in the oven. The online pyro camera (98) of the sensor box (9) sends the image to the expert system. With simple statistical machine teaching methods, the abnormality is revealed and the computer sends the cooking finisher (5). This machine is capable of any kind of actions. In this case a spatula is armed on the 6-axis system. Then the finisher with slow actions solves the problem. This could be done automatically or through the system joysticks (82) at the initial training stages.

All the above cooking finisher (5) actions could be carefully designed an embedded in the recipe for fully automatic unattended operation. This is the primary cooking finisher (5) task.

The guided cooking by a chef is a non-automatic procedure performed with a human simple external guidance. This is stored in the expert system memory. In a more sophisticated example the system can stop the bad smell of burning meat. Always the sensor box (9) reads and records the gases and color of the cooking. Once the theory could be useful the operator adds to the expert system (8) the new born theory of dry cooking burning gases. The form of this addition is a number of photographs and chemical descriptions. The actual burning meat smell is compared to the memory and an exact match is occurred. Immediately the computer commands to open the oven door and turn it off.

\section{Advanced Cooking}

Analyzing the cooking gases electromagnetic spectrum is a futuristic option (Hirano, 2013). The gases image analysis is one of the hundreds expert system (5) options. It uses simple artificial intelligence techniques of pattern matching in huge databases. At the current initial invention, we limit to use this option to record millions of actual cooks.

The sensor box (9) device analyses two cooking elements with two totally different paths gases and light.

Traditionally the chef examines the food surface and evaluate various food status. The spectrum coverage of the device exceeds human eye with Near Ultraviolet, Visible and Mid infrared from $100 \mathrm{~nm}$ to $5 \mu \mathrm{m}$. The light emission travels through the casserole transparent surface (101), sensor box (9) heat insulation glass and it finally reaches the light sensors 


\section{Macrothink}

(97,98 and others). Data are sent through the bus (113) the concentrator (111) and pot computer (112) to the central computer.

The gases path (102) starts from the pot hole, gases enter the sensor box through the heat isolation cover (91) and speed reduction grid (99) and split up to the open air and to the sensors area. The gases sensors $(93,94,95,96)$ measure accordingly and report to the computer.

The communications and commands flow are based on an inexpensive RFID tag (65) and Wi-Fi accordingly. The kitchen area is scanned (71) continuously and stores the spatiotemporal data to the database. All actions are based on this data. Then the Wi-Fi system transmits (38) the action commands to the kitchen machinery in an interactive endless procedure.

The expert system is the heart of the invention. It handles all minor and major details for successfully cooking. Operations are:

- Translate the recipe pseudo language to programming language and to the machinery vehicle and pot instructions,

- Calculate spatiotemporal positioning data for all system hardware.

- Calculate nutrition and calories information.

- Stores all data for future use.

And hundreds other useful or fancy functions.

The crucial expert system function is to initially write, read and execute the recipe. A good recipe is the cornerstone of the invention.

At the first step a normal recipe is converted to a logical recipe without spatiotemporal inconsistent and discrepancies.

Then every recipe paragraph is converted to recipe language macro statements. For example, the paragraph "heat the oil" is transliterated to

- $\quad$ open cover of pot 44

- $A=x y z 3 D$ structure of pot

- $\mathrm{B}=$ the center $\mathrm{xx}$ of $\mathrm{A}$

- Grab oil and dosing head number 33

- Move dosing head 33 to point B

- $\quad$ Release the valve of head number 33

- Turn on the heat plate

- $\quad$ Suspend 5 minutes

Then the token compiler converts the program into machine executable code. Machine executable here is not an .exe program file but commandments to be executed by the hardware. These commands are hardware depended and generally are very primitive level for inexpensive systems. The recipe authoring is a programmer in cooperation with the chef task.

Due to the invention global design the operator could replace a lot of traditional equipment and procedures. For example, a deep fryer is already here using computer programming intelligence with simple steps: 


\section{$\underline{\Lambda \text { Macrothink }}$}

A normal pot (1) with oil and potatoes are ready for the next step. The stirrer takes his wide position and (68) help to unload only the oil to another pot. Then the stirrer changes in position narrow (70) and return to the other side. Finally, (71) the stirrer transforms again in position wide (72) and it pushes the potatoes to the oven (12).

There is a number of problems or design irregularities that has been solved partially.

The procedure to fill in the containers (1) with food from the selves, the refrigerator and the deep fritz is not automatic. Every food item is divided is appropriate pieces, put in a container type (1), it is weighted and marked with an RFID tag. Then a vehicle type (3) distributes the container to the storage room.

It is impossible to design a fully automatic system. The difficult, costly or impossible systems very easily could be replaced by a simple human intervention.

The sensor box hardware today exceeds the capabilities of cooking science. This is normal for the Cooking full spectrum emissions and gases it is not a science mater. Such features are included on this machine because the question "Which comes first the chicken or the egg?" has not answer. The sensor box accumulates connoisseur knowledge in every cooking circle.

Containers and pots need washing. Due to pot connection to DC and data complexity pots need disassembly prior washing. This is only possible by the operator although a normal professional cleaning machine does the actual cleaning.

At the engineering stage of the invention alpha test a number of parts will be replaced by more efficient subsystems.

The electric and mechanic parts are commercially available from the industry today but there are a lot of implementation details to be solved, both at a technical and cost benefit level.

All type of software system, application, expert system and hardware commands need design from scratch.

\section{Conclusion, the Data Analytics in Connoisseur Lab}

Various tools exist to measure the kitchen connoisseur performance (Otles, 2016, Nollet, 2004). Molecular gastronomy researchers focus on emerging technologies (Barhan, 2010, Spence 2018) but not in next generation approach.

The future of computing and food vision (Obrist, 2018, Obrist, 2017, Velasco, 2017, 2018, Spence, 2017) are implemented today in the firmware of ABRAHAM. However hardware is the barebone of the system but brainware is the system heart.

We evaluated Data Science connoisseur research; Valente (2018) studied wine sensory space; Sörensen (2018) studies public food awareness; Fooladi (2019) interacts the conflict between chef and Scientist; Radermacher (2018) defines a generalized data science concept;

From all the above it is clear that Big connoisseur Data is urgently needed. At this preliminary stage we use ABRAHAM as data collection system. We don't cook it is very expensive with unknown results. A Big Data Analytics cooking example could be:

The semi-automatic joystick performs all food processing phases. During these phases Big Data are collected from the hundreds of system sensors. For a simple spaghetti with cooking time of 20 minutes several million of data are stored in system memory. The spaghetti is served and tasted by the customer. Any suggestion like "it needs more cooked tomato 


\section{MInstitute Macrothink $_{\text {Int }}$}

sausage" it is evaluated by the system. The next meal of the same person will be processed exactly the same with 5 minutes more boiling the tomato sausage.

Actually, the ABRAHAM is a subroutine driven cooking Big Data Analytics platform for the chef of the future. With Abraham blessing we hope to prepare it for the international market.

\section{References}

Barham, P., Edwards, J. S., \& Schafheitle, J. M. (2001). The science of cooking. Food Service Technology, 1(3), 183-184. https://doi.org/10.1046/j.1471-5740.2001.d01-2.x

Barham, P., Skibsted, L. H., Bredie, W. L., Bom Frøst, M., Møller, P., Risbo, J., ... Mortensen, L. M. (2010). Molecular gastronomy: A new emerging scientific discipline. Chemical Reviews, 110(4), 2313-2365. https://doi.org/10.1021/cr900105w

Boysen, N. (2018). Optimizing automated sorting in warehouses: The minimum order spread sequencing problem. European Journal of Operational Research, 270(1), 386-400. https://doi.org/10.1016/j.ejor.2018.03.026

Brandl, M. (2016). Position estimation of RFID-based sensors using SAW compressive receivers. Sensors and Actuators A: Physical, 244, 277-284. https://doi.org/10.1016/j.sna.2016.04.032

Chang, F.-1. (2007). Research on Order Picking Optimization Problem of Automated Warehouse. Systems Engineering - Theory \& Practice, 27(2), 139-143. https://doi.org/10.1016/S1874-8651(08)60015-0

Cinar, D. (2017). Scheduling the truckload operations in automated warehouses with alternative aisles for pallets. Applied Soft Computing, 52, 566-574. https://doi.org/10.1016/j.asoc.2016.10.013

Doiro, M. (2017). ERP-machining centre integration: a modular kitchen production case study. Procedia Manufacturing, 13, 1159-1166. https://doi.org/10.1016/j.promfg.2017.09.178

Erasmus, A. C. (2013). Culinary Nutrition: The Science and Practice of Healthy Cooking by Jacqueline B. Marcus (2013). Oxford, UK. Published by Elsevier. International Journal of Consumer Studies, 37(4), 465-466. https://doi.org/10.1111/ijcs.12037

Fooladi, E., Hopia, A., Lasa, D., \& Arboleya, C. (2018). Chefs and researchers: Culinary practitioners' views on interaction between gastronomy and sciences. International Journal of Gastronomy and Food Science. https://doi.org/10.1016/j.ijgfs.2018.11.003

Hamada, R., Okabe, J., Ide, I., Satoh, S. I., Sakai, S., \& Tanaka, H. (2005, November). Cooking navi: assistant for daily cooking in kitchen. In Proceedings of the 13th annual ACM international conference on Multimedia (pp. 371-374). ACM. https://doi.org/10.1145/ 1101149.1101228

Hirano, S. H., Brubaker, J. R., Patterson, D. J., \& Hayes, G. R. (2013, September). Detecting cooking state with gas sensors during dry cooking. In Proceedings of the 2013 ACM international joint conference on Pervasive and ubiquitous computing (pp. 411-414). https://doi.org/10.1145/2493432.2493523 


\section{Macrothink}

Jones, T. (2008). Culinary calculations: simplified math for culinary professionals. John Wiley \& Sons.

Marcus, J. B. (2013). Culinary nutrition: the science and practice of healthy cooking. Academic Press.

Nicolas, L. (2018). Order batching in an automated warehouse with several vertical lift modules: Optimization and experiments with real data. European Journal of Operational Research, 267(3), 958-976. https://doi.org/10.1016/j.ejor.2017.12.037

Nollet, L. M. (2004). Handbook of Food Analysis. -3 Volume Set. CRC Press.

Obrist, M., Marti, P., Velasco, C., Tu, Y., Narumi, T., \& Holten Møller, N. L. (2018, May). The future of computing and food. In AVI'18 Proceedings of the 2018 International Conference on Advanced Visual Interfaces. Association for Computing Machinery. https://doi.org/10.1145/3206505.3206605

Otles, S. (2016). Handbook of food analysis instruments. CRC Press.

Pereboom, D. (2009). Free will, love, and anger. Ideas y Valores, 58(141), 169-189.

Radermacher, W. J. (2018). Official statistics in the era of big data opportunities and threats. International Journal of Data Science and Analytics, 1-7. https://doi.org/10.1007/s41060-018-0124-z

Royo, J. (2013). Influence of the Position of a UHF-RFID Tag Relative to the Antenna in the Information Reading. Procedia Engineering, 63, 151-157. https://doi.org/10.1016/j.proeng.2013.08.269

Schneider, M. (2007, September). The semantic cookbook: sharing cooking experiences in the smart kitchen. In Intelligent Environments, 2007. IE 07. 3rd IET International Conference on (pp. 416-423). https://doi.org/10.1049/cp:20070401

Sörensen, P. M., \& Mouritsen, O. G. (2018). Science education and public understanding of science via food, cooking, and flavour. International Journal of Gastronomy and Food Science. https://doi.org/10.1016/j.ijgfs.2018.11.006

Spence, C., \& Youssef, J. (2018). Assessing the long-term impact of the molecular gastronomy movement on haute cuisine. International Journal of Gastronomy and Food Science. https://doi.org/10.1016/j.ijgfs.2018.10.001

Spence, C., Obrist, M., Velasco, C., \& Ranasinghe, N. (2017). Digitizing the chemical senses: possibilities \& pitfalls. International Journal of Human-Computer Studies, 107, 62-74. https://doi.org/10.1016/j.ijhcs.2017.06.003

This, H. (2010). Kitchen mysteries: Revealing the science of cooking. Columbia University Press.

Valente, C. C., Bauer, F. F., Venter, F., Watson, B., \& Nieuwoudt, H. H. (2018). Modelling the sensory space of varietal wines: Mining of large, unstructured text data and visualisation of 


\section{Macrothink}

style patterns. Scientific Reports, 8(1), 4987. https://doi.org/10.1038/s41598-018-23347-w

Velasco, C., Nijholt, A., \& Karunanayaka, K. (2018). Multisensory Human-Food Interaction. Frontiers in psychology, 9, 796. https://doi.org/10.3389/fpsyg.2018.00796

https://doi.org/10.3389/fpsyg.2018.00796 Velasco, C., Nijholt, A., Obrist, M., Okajima, K., Schifferstein, R., \& Spence, C. (2017, November). MHFI 2017: 2nd international workshop on multisensorial approaches to human-food interaction (workshop summary). In Proceedings of the 19th ACM International Conference on Multimodal Interaction (pp. 674-676).

Wolke, R. L., \& Parrish, M. (2002). What Einstein told his cook: kitchen science explained. WW Norton \& Company.

\section{Copyright Disclaimer}

Copyright for this article is retained by the author(s), with first publication rights granted to the journal.

This is an open-access article distributed under the terms and conditions of the Creative Commons Attribution license (http://creativecommons.org/licenses/by/3.0/). 